\title{
Study on Countermeasures of the Logistics Efficiency of Fresh Agricultural Products in China
}

\author{
Yue Zhang \\ Tianjin Agricultural University, Tianjin, 300384, China
}

Keywords: Fresh agricultural products, Logistics status, Logistics efficiency

\begin{abstract}
At present, because of the rather late start of the market construction of fresh agricultural products in our country, the logistics efficiency of fresh agricultural products is also relatively low, which has a very unfavorable effect on the market value and cargo movement, even leads to severe loss during the process of cargo movement. This is not only harmful to the social and economic benefits of producers, but also causes customers to bear a higher price. Therefore, in order to give consideration to both the producers and consumers' basic benefits, and further improve market competitiveness of fresh agricultural products, we must take some measures to improve the logistics efficiency of fresh agricultural products in our country to provide a higher quality service for the public.
\end{abstract}

\section{Introduction}

With the rapid development of China's economy and society, people's living standard has been improved significantly. To a certain extent, it leads to people's increasing demand of materials. People's consumption concept also changed from the traditional single living consumption to the pluralism and high-speeding consumption in the modern society. Manifesting on the fresh agricultural products is to ask for its freshness, nutrition, safety and diversity and meets different demands of people in different class. However, fresh agricultural products are easy to be corrode, which greatly limits the specific time and radius of its logistics, has a very important effect on the improvement of its logistics efficiency, even will restrict the further development of the fresh agricultural products industry. Therefore, it is necessary to make a scientific and rational analysis on the factors that affect the logistics of fresh agricultural products, and take corresponding measures to make an important guidance on its logistics practice.

\section{The necessity of improving the present logistics efficiency of fresh agricultural products in China}

\section{It is good for both the producers and the consumers' vital interests}

Because fresh agricultural products are easy to be corrode, so improving logistic efficiency can effectively shorten the logistics time and further control the loss during the process of transportation, realize the reduction of logistics cost and capital reduction, further to save capital and promote industry development. And guaranteeing the freshness of fresh agricultural products can effectively improve its commercial value to increase the real income of the producers. Meanwhile, bring modern high technology into the logistics of fresh agricultural products can greatly improve its quality safety and reduce logistics cost, and make consumers buy higher quality products with lower price to guarantee their vital interests.

\section{It is necessary for the further improvement of competitiveness of fresh agricultural products industry}

With the rapid development of economic globalization, fresh agricultural products industry in China begins to face the more and more drastic competitive environment, compared with freash agricultural products in China, foreign fresh agricultural products have a certain competitive advantage on the quality, safety, brand and package[1]. In addition, influenced by China's official join into WTO, tariffs in China began to reduce, which led to the competitive advantage of the 
domestic fresh agricultural products also decreased year by year. Under this social background, it is extremely urgent to improve logistics efficiency of Chinese fresh agricultural products to increase ins commercial value, further to improve its competitiveness.

\section{Current logistics situation of Chinese fresh agricultural products}

\section{Production of fresh agricultural products is still fragmented}

Our country has gradually realized the importance of the development of fresh agricultural products and set up a number of production bases. But the specific production of fresh agricultural products is still distributed to individual farmers, which has a bad effect on the production quality. Because individual farmers chase for benefit maximization during the production, and our government have no effective control on the quality of fresh agricultural products, therefore, individual farmers normally pay attention to the quantity and ignore the quality during the actual production process, which makes the quality of a large number of commodities in our fresh agricultural products market cannot be guaranteed. Even though there are some producers who care the products' quality and produced a number of high quality agricultural products, they also cannot gain more profit in sales for their relative small scale. Therefore, most Chinese agricultural products face the problems of pesticide, veterinary drug or heavy metal content exceeding standard, which gradually makes the food safety become the forth social problem of the whole society.

\section{Fresh agricultural products are with high loss rate in the logistics link for its low processing ability}

Commodity processing of Chinese agricultural products is commonly $1 \%$, fresh storage proportion is less than $20 \%$, processing rate has remain around $10 \%$, there is a large gap to the international advanced level. Low processing level and ability have a direct influence on the commercial value of products. Relevant investigation result showed that loss rate of fruit and vegetables in Chinese market during the transportation and storage is around 28\%, while that of the developed countries is normally controlled under 5\%[2]. Especially because of the advanced American cold link logistics technology, products can be processed, transported and kept under the low temperature condition after harvest, therefore, loss rate of American fresh agricultural products during the whole logistics link is even less than $2 \%$.While in our country, cold link logistics technology started relatively late, until now, there is no systematic and scientific cold logistics link, logistics processing of most agricultural products are under the normal temperature, therefore, annual loss during this link can reach 75 billion Yuan. The weak development of our cold link logistics technology of fresh agricultural products leads to its logistics block and wasting of resources.

\section{Lag behind of the logistics infrastructure lead to the high logistics cost of fresh agricultural products}

Our country’ transportation infrastructure in the rural areas is relatively lagging behind, the overall interconnectivity degree of road network is relatively affected, there's no way for the professional transportation. According to statistics, in our transportation industry, over $70 \%$ of all road transport vehicle is convertible, less than $30 \%$ is strong sealed van vehicle, which is not good for the development of logistics of fresh agricultural products. At the same time, in the whole transportation activities, highway refrigerated transport amount is much different from that of railway transport, which will have influence on the transport time and increase the logistics cost, it is not good for the development of modern logistics enterprises. Besides, storage warehouse for fresh agricultural products in our country is normally bungalow warehouse, storage facilities are relatively simple, normally without modern storage equipment for cold storage, preservation and gas condition, which makes the cost of keeping fresh during the logistics process is too high and makes harmful effect on the logistics profits[3].Especially when a kind of fresh agricultural product gets into the market, it will bring a huge negative effect on the producers' profit for the impeded logistics and low processing ability. 


\section{Measures to improve the present logistics situation of fresh agricultural products in China}

\section{Order production to promote agricultural products production towards to large scale production}

Because the production and operation processes of agricultural products in our country are relatively disperse, so the application of standard and regulated production and logistics is very difficult. At the same time, with the further development of reform and opening up process and the change of national consumer demand, both the domestic and oversea market desire standardization and modernization of fresh agricultural products. In order to guarantee the quality and improve competitiveness, various countries in the world have made scientific and clear standards for the production and operation process of fresh agricultural products, and in the process of development these standards become more and more strict to guarantee the quality and safety and improve commercial value of fresh agricultural products, so as to improve the competitiveness in the international markets. Relative departments should take the production way of "Enterprise + Base" to start from the source of logistics to improve quality, safety finally to realize real standardized production[4] of fresh agricultural products through scale and standard management.

\section{Develop the advanced way of cold-chain logistics}

Logistics of fresh agricultural product is much different from that of traditional industrial products for it is easy to be corrode and hard for saving. Normally, fresh agricultural products main have the following physical features: easy to be corrode and damaged; unite price is relatively low but with large volume; product specification, quality and shape is not unified. These features not only limit the time and radius of logistics, but also have requirements on the number of transferring, it is better to decrease transfer times in the logistics process. Especially some more fresh products have more strict requirements on logistics. While cold-chain logistics can make low temperature processing of fresh agricultural products, guarantee the quality through different chains-harvest, storage, processing, delivery and sales, maximize maintain the freshness, decrease transportation loss and gradually improve commercial value and logistics efficiency.

\section{Greatly develop the third party logistics service}

According to our country's logistics development situation of agricultural products, logistics efficiency can be improved through improving logistics level of the third party. Operation mode of the third party logistics is with the features of profession, concentrate information treatment, simple logistics chains and relatively higher delivery efficiency. Developing the third logistics service party cannot only effectively guarantee freshness but also help enterprises reduce cost and guarantee timely supply of products, even can expand the logistics radius and time to promote the profession and standardization of logistics. Besides, the third logistics service party can promote the development of transportation, storage and delivery of fresh agricultural products, promote the logistics towards to be professional, systematic and standardize, then to create good conditions for the logistics system of fresh agricultural products.

\section{Develop supermarket sales mode}

With the gradual improvement of people's living standard in our country, people's requirement on the quality, freshness and safety of fresh agricultural products also has been improved accordingly, traditional vegetable retail market is unable to meet the increasing consumer demand. Supermarket gradually becomes the main sales place for fresh agricultural products for its modern evolution and standard operation mode that provides strong traceability of the products in the logistics chain. With a good credibility, around 70\% fresh agricultural products of western developed countries are sold in the supermarket, which effectively shortened unnecessary logistics links and help to improve logistics efficiency gradually. Meanwhile, construction of logistics chain makes supermarket become the terminal of modern logistics chain, and for its strict management and monitoring system, compared with individual peddlers, supermarket has the processing condition and further improves their enthusiasm for agricultural products processing. This can not only meet the fast-faced living 
demands of city people, but also improve the commercial value of fresh agricultural products to increase enterprise income.

\section{Bring in different kinds of advanced logistics technology}

Firstly, bring in origin coding system of fresh agricultural products. Identify fresh agricultural products after treatment in different processing chains in logistics and wholly collect the original identification information with all other information to label on the stage finished products to provide convenience for next processing. In this way, if consumers find relevant quality or safety problems when using, they can trace back basing on the identification information to find out problems and improve logistics efficiency.

Secondly, explore cold storage technology for fresh agricultural products. Improvement of cold storage technology can effectively decrease product loss during logistics process, reduce logistics cost and improve efficiency. At present, widely-used cold storage technology in our country mainly includes gas condition, mechanical refrigeration storage technology, traditional hoard preservation technology and the application of plastic wrap and preservative, which have a large gap to the advanced preservation technology in the world, it not only unable to decrease loss in the logistics process, it will also increase logistics process and prolong the logistics time and bad for the improvement of logistics efficiency. Therefore, we should actively explore advanced high temperature/high pressure preservation technology, ozone gas condition preservation technology, biological preservation technology and nanometer preservation technology to shorten logistics chains and improve logistics efficiency.

\section{Conclusion}

In conclusion, from the long-term benefit of logistics industry of fresh agricultural products, logistics efficiency has to be improved, further to guarantee quality and safety of products to improve the commercial value through shortening logistics chains and times and promoting the standardization and modern development of logistics of fresh agricultural products.

\section{Acknowledgments}

This paper is assisted by the humanity and social science research project "Research on the Logistic Mode Optimization of Agricultural products Based on the Integration of Beijing, Tianjin and Hebei Province” of colleges and universities in Tianjin city, Project No.: 20142410

\section{References}

[1] Luo Xuqin, Tong Xiaohu, Wang Qijun and son on. Study on the Logistics Efficiency of Fresh Agricultural Products-Set Supermarket as Study Object. China Agricultural Information, 2014(5):48-50.

[2] Dai Dan. Analysis on Logistics Efficiency of Fresh Agricultural Products-Set Supermarket in Hangzhou as Study Object. Guide of Sci-tech Magazine, 2012(16):7-8.

[3] We Biqin, Yao Shunbo. Study on Logistics Optimization of Fresh Agricultural Products Led by Chain Supermarkets. Xinjiang State Farms Economy, 2008(7):31-34.

[4] Yang Baohong, Guo Honglian, Wei Guochen and so on. Discussion on Improving Logistics Efficiency of Fresh Agricultural Products-Enlightenment from Shenzhen "Buji Mode”. Logistics Technology, 2009, 28(2):28-30,37.

[5] Wang Xuhui, Wen Jingyi. Logistics Efficiency of Agricultural Products in China and Its Regional Deffierence-SFA Analysis Based on Panel Data of Provinces. Contemporary Economy \& Management, 2015,37(1):26-32. 